\title{
Influence of Plasma Cortisol and Other Laboratory Parameters on Nonalcoholic Fatty Liver Disease
}

\author{
Authors \\ J. M. Hubel ${ }^{1}$, S. A. Schmidtt ${ }^{2}$, R. A. Mason ${ }^{3}$, M. M. Haenle ${ }^{1}$, S. Oeztuerk ${ }^{1}$, W. Koenig ${ }^{4}$, B. O. Boehm ${ }^{5}$, \\ W. Kratzer ${ }^{1}$, T. Graeter ${ }^{2}$, M. Flechtner-Mors ${ }^{6}$; the EMIL-Study Group \\ Affiliations \\ Affiliation addresses are listed at the end of the article
}

\author{
Key words \\ - cortisol \\ - NAFLD \\ - ultrasonography \\ cross-sectional study
}

received 15.07 .2014

accepted 26.08.2014

Bibliography

DOI http://dx.doi.org/

10.1055/s-0034-1389982

Published online:

October 8, 2014

Horm Metab Res 2015;

47: 479-484

(c) Georg Thieme Verlag KG

Stuttgart · New York

ISSN 0018-5043

Correspondence

Prof. Dr. med. W. Kratzer

Zentrum für Innere Medizin Klinik für Innere Medizin I Universitätsklinikum Ulm Albert-Einstein-Allee 23 $89081 \mathrm{Ulm}$

Germany

Tel.: +49/731/500 44730

Fax: $+49 / 731 / 50044620$

Wolfgang.Kratzer@uniklinikulm.de

\section{Abstract \\ $\nabla$}

The objective of the present study was to analyse the association between the plasma cortisol concentration and nonalcoholic fatty liver disease (NAFLD). A total of 1326 subjects (age 18-65 years) were examined in the context of an epidemiological study of a population-based random sample. Medical history and anthropometric data of 662 women and 664 men were documented. In addition, laboratory examinations were performed and the fat concentration of the liver was esti-

\begin{tabular}{ll}
\hline \multicolumn{2}{l}{ Abbreviations } \\
$\nabla$ \\
ALT & Alanine aminotransferase \\
AP & Alkaline phosphatase \\
AST & Aspartat aminotransferase \\
BMI & Body-mass-index \\
EMIL & Echinococcus multilocularis in \\
& Leutkirch \\
GGT & $\gamma$-glutamyl-transferase \\
HD & High-density lipoprotein \\
MRS & Magnetic resonance spectroscopy \\
NAFL & Nonalcoholic fatty liver \\
NAFLD & Nonalcoholic fatty liver disease \\
NASH & Nonalcoholic Steatohepatitis \\
WHR & Waist-to-hip-ratio \\
11 $\beta$-HSD1 & $11 \beta$-Hydroxysteroid dehydrogenase \\
& type 1
\end{tabular}

\section{Introduction}

$\nabla$

Nonalcoholic fatty liver disease (NAFLD) is characterised by a liver triglyceride content $>5 \%$ by weight (liver fat content of the liver $>95^{\text {th }}$ percentile for normal-weight, healthy subjects) or the presence of fat droplets the cytoplasm of $>5 \%$ of hepatocytes [1]. With a prevalence of up to $30 \%$

*These authors contributed equally to this work. mated by ultrasound examination. Mean cortisol concentration in plasma was $260.4 \pm 156.8 \mathrm{nmol} / \mathrm{l}$ for women and $295.8 \pm 161.2 \mathrm{nmol} / \mathrm{l}$ for men. NAFLD was identified in $17.7 \%$ in women and $35.1 \%$ in men. Plasma cortisol concentration showed no association with the existence of NAFLD. NAFLD correlated positive with age, body-mass index (BMI), waist-to-hip-ratio (WHR), alanine aminotransferase (ALT), and triglycerides. The present study failed to establish any association of plasma cortisol concentrations and NAFLD.

of adults in the general population, NAFLD represents the major chronic liver disease in Western industrial nations [2]. The prevalence may reach $70 \%$ and even exceed $90 \%$ in patients with diabetes and extreme obesity [3]. The degree of hepatic steatosis can be detected by imaging techniques. For example, magnetic resonance spectroscopy (MRS) allows for exact identification of the fat content in the liver [4]. Ultrasonography diagnoses NAFLD with a sensitivity of $85-94 \%$ and a specificity of $84-93 \%[5,6]$. NAFLD includes both benign, nonalcoholic fatty liver (NAFL) and nonalcoholic steatohepatitis (NASH), which is accompanied by histological evidence of inflammatory markers. Ultrasound cannot differentiate between NAFL and NASH. The latter may be associated with progressive fibrosis and may ultimately lead to cirrhosis of the liver and hepatocellular carcinoma [7]. Histological examination of the organ is required for identifying the exact state of the liver disease [8].

Possible causes for NAFLD include an increased supply of fat with the diet [9], an increased supply of free fatty acids from the adipose tissue that reaches the liver and increased de novo lipogenesis in the liver $[1,10]$. In addition, an increased supply of carbohydrates may promote development of NAFLD by increasing the de novo synthesis of fat in the liver [1,11-13]. In particular, an 
increased intake of fructose increases the fat content of the liver by stimulating hepatic de novo lipogenesis [14]. Whether this is due to insulin resistance, which is closely associated with an increased fat content of the liver [15], or as a result of a NAFLD remains unclear [1].

Genetic factors are also known to play a role in the pathogenesis of NAFLD. For example, a high percentage of children with NAFLD have siblings and parents who share this disorder [16]. The genetical basis, however, remains largely unknown [17]. Glucocorticoids and the regulation of glucocorticoid metabolism may also play an important role in the pathogenesis of NAFLD. Hepatic changes in glucocorticoid metabolism attributable to an increased cortisol production have been demonstrated in patients with NAFLD [18].

Objective of the present study, which was performed in the context of an epidemiological study of an urban population in Leutkirch (Southwestern Germany), was to analyse the association of plasma cortisol concentrations and NAFLD.

\section{Participants and Methods}

$\nabla$

\section{Participants}

The EMIL study (Echinococcus multilocularis in Leutkirch), a cross-sectional study of the prevalence of Echinococcus multilocularis infection in an urban population-based sample in Southwestern Germany, was conducted over a 4-week period in November and December, 2002. A secondary objective was to estimate the prevalence of NAFLD in the general population. Four-thousand inhabitants randomly selected out of an urban population of 22093 inhabitants were contacted with the request to take part in the study. Of these, a total of 3893 persons aged 10-65 years were successfully contacted. The study was conducted in accordance with the principles of the Helsinki Declaration and the guidelines of Good Clinical Practice (GCP). The study was approved by the ethics committee the Landesärztekammer Baden-Württemberg. All subjects were informed about the study and its procedure in detail. After adequate time for consideration and before the beginning of the study, all participants provided written consent to participate in the study. In order to compare the study results with those of others, only the results of the adults were considered in this study. Participants with self-reported daily alcohol consumption exceeding $60 \mathrm{~g} /$ day in men and $20 \mathrm{~g} /$ day in women were not included in the study. Subjects with acute or chronic liver diseases and disorders with potential liver involvement, (autoimmune or metabolic) diseases of the heart, lung, gastrointestinal tract and kidney, as well as those with hormonal disorders and those treated with glucocorticoids were excluded from the study. However, women receiving estrogen therapy $(n=845)$ were not excluded. Subjects with a fasting time less than $1 \mathrm{~h}$ were also not considered because of the food-dependent influence on the cortisol level. Also, subjects whose records were incomplete due to missing data were not included in the statistical analysis. The results of the remaining 1326 subjects [662 (49.9\%) women and $664(50.0 \%)$ men, age 18-65 years] were included in the statistical analysis ( $\bullet$ Fig. 1).

\section{Examination methods}

Subjects' medical histories, laboratory test results, and anthropometric data (body-mass index (BMI) and waist-to-hip ratio (WHR) were calculated according to the WHO recommendations

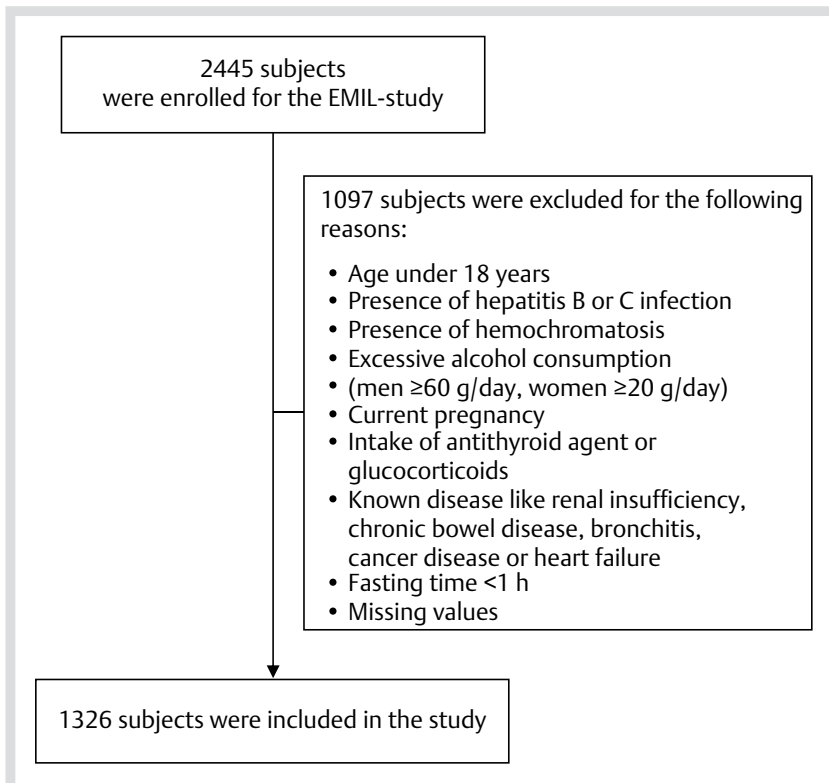

Fig. 1 Flow of the subjects across the study.

[5]\} were recorded and ultrasound examination of the liver was performed.

\section{Ultrasonography examination}

Diagnosis of NAFLD was made based on sonographic comparison of the hepatic and renal parenchyma, the liver's dorsal echo attenuation, the penetration of the diaphragm and the ability to assess the hepatic vessels [6,7]. Based on these findings, the disease was graded as no NAFLD (normal, grade 0), and NAFLD grades I, II, and III.

Although liver biopsy remains the gold standard for confirming the diagnosis of NAFLD [9] and for measuring the fat content in this organ, in clinical practice, ultrasound has been proven valuable for assessing liver fat content. For the diagnosis of NAFLD, ultrasound has a reported specificity of $84-93 \%$ and a sensitivity of $85-94 \%[6,7,9]$. The sonographic examination of fatty liver is a noninvasive and low-cost practical method appropriate for surveys under field conditions [19].

\section{Laboratory testing}

Phlebotomy was performed between 1 PM and 9 PM with fasting times of not less than one longer than $8 \mathrm{~h}$ after subjects' last meal. Samples containing $25 \mathrm{ml}$ of whole blood were obtained from a cubital vein. Tubes were sent coded and cooled to the laboratory of the Department of Clinical Chemistry of the University Hospital of Ulm and processed on the same day. Aliquot samples were deep-frozen for replicate tests in case of need. Triglycerides, cholesterol, HDL cholesterol, AP, AST, ALT, and GGT were measured using the Dimension XL unit (Dade Behring Inc., Newark, DE, USA) on the same day. Following completion of the study, total cortisol concentrations of the until then deep-frozen serum samples were determined using the Cobas e411 testing unit (Roche) in samples that remained frozen until processing.

\section{Statistical analysis}

The calculations were performed using the Statistics Analysis Software (SAS) statistical software package (version 9.2; SAS Institute, Cary, NC, USA). Data were first analysed descriptively. Qualitative features are given with absolute and relative fre- 
quencies, quantitative variables are given with mean and standard deviation. In order to detect differences between female and male subjects, the Wilcoxon rank sum test (Mann-Whitney U-test) was used for continuous variables, while, for categorical variables, the $\mathrm{X}^{2}$-test was used. In a further analysis, cortisol values were divided into 3 groups of equal size (tertiles) for subjects with and without hepatic steatosis. The ranges of the 3 respective tertiles for subjects without hepatic steatosis were as follows: first tertile: $11.8-184 \mathrm{nmol} / \mathrm{l}$; second tertile: $185-$ $319 \mathrm{nmol} / \mathrm{l}$; third tertile: $320-827 \mathrm{nmol} / \mathrm{l}$, respectively. For subjects with hepatic steatosis, the ranges of the 3 respective tertiles were as follows: first tertile: $16.4-178 \mathrm{nmol} / \mathrm{l}$; second tertile:

Table 1 Characteristics of the subjects.

\begin{tabular}{|c|c|c|c|}
\hline & $\begin{array}{l}\text { Female } n=662 \\
(49.9 \%)\end{array}$ & $\begin{array}{l}\text { Male } n=664 \\
(50.0 \%)\end{array}$ & p-Value \\
\hline \multicolumn{4}{|l|}{ Demographics } \\
\hline Age (years) & $41.8 \pm 12.6$ & $41.2 \pm 12.7$ & 0.3925 \\
\hline BMI $\left(\mathrm{kg} / \mathrm{m}^{2}\right)$ & $24.9 \pm 5.1$ & $26.2 \pm 4.2$ & $<0.0001$ \\
\hline WHR & $0.8 \pm 0.1$ & $0.9 \pm 0.1$ & $<0.0001$ \\
\hline \multicolumn{4}{|l|}{ Laboratory parameters } \\
\hline $\operatorname{ALT}(\mathrm{U} / \mathrm{I})$ & $12.4 \pm 4.6$ & $18.3 \pm 9.4$ & $<0.0001$ \\
\hline AST (U/I) & $8.6 \pm 2.4$ & $10.6 \pm 4.4$ & $<0.0001$ \\
\hline GGT (U/I) & $9.8 \pm 11.0$ & $17.1 \pm 16.5$ & $<0.0001$ \\
\hline $\mathrm{AP}(\mathrm{U} / \mathrm{I})$ & $78.8 \pm 25.7$ & $85.1 \pm 19.5$ & $<0.0001$ \\
\hline Total cholesterol (mmol/l) & $5.5 \pm 1.0$ & $5.5 \pm 1.1$ & 0.3089 \\
\hline Triglycerides (mmol/l) & $1.3 \pm 0.8$ & $1.9 \pm 1.4$ & $<0.0001$ \\
\hline Total cortisol (nmol/I) & $260.4 \pm 156.8$ & $295.8 \pm 161.2$ & $<0.0001$ \\
\hline \multicolumn{4}{|l|}{ Disorders } \\
\hline Hepatic steatosis n (\%) & $117(17.7 \%)$ & $233(35.1 \%)$ & $<0.0001$ \\
\hline \multicolumn{4}{|l|}{ Values are mean $\pm S D$} \\
\hline \multicolumn{4}{|c|}{$\begin{array}{l}\text { ALT: Alanine aminotransferase; AP: Alkaline phosphatase; AST: Aspartat aminotrans- } \\
\text { ferase; GGT: Gamma glutamyltransferase; HDL: High-density lipoprotein; WHR: } \\
\text { Waist-to-hip-ratio }\end{array}$} \\
\hline
\end{tabular}

180-321 nmol/l; third tertile: $324-816 \mathrm{nmol} / \mathrm{l}$. In order to demonstrate differences between the 3 groups, the Kruskal-Wallis test for constant variables and the $\mathrm{X}^{2}$-test for categorical variables were used. Multiple logistic regression was used to calculate the associations between the determining factors and NAFLD. All statistical calculations were performed 2-tailed; statistical significance was set at $\alpha=0.05$.

\section{Results}

$\nabla$

The study collective consisted of 1326 subjects [662 (49.9\%) women and 664 (50.0\%) men; age 18-65 years, mean $41.5 \pm 12.7$ years]. Broken down by gender, there were statistically significant differences in terms of the anthropometric variables BMI and WHR, in the prevalence of NAFLD, and in the laboratory parameters ALT, AST, GGT, AP, and triglycerides. By contrast, no significant differences were found between men and women in terms of age and total cholesterol ( $\bullet$ Table 1 ). Sonographic evidence of NAFLD was returned in 353 subjects (26.4\%): here, men showed a higher prevalence than women $(35.1 \%$ vs. $17.1 \%$; $\mathrm{p}<0.0001$ ).

Total cortisol concentrations were further studied in subjects with and without hepatic steatosis. Cortisol values for subjects with and without hepatic steatosis were grouped in tertiles and analysed. There was a statistically significant difference for the parameters gender, age, ALT and total cholesterol among subjects without hepatic steatosis. In the group of subjects with evidence of hepatic steatosis there was no significant difference (๑ Table 2).

The association between NAFLD and possible risk factors are listed in $\odot$ Table 3. Increasing age was positively associated with NAFLD ( $p<0.0001)$. The risk of NAFLD increased with increasing BMI $(\mathrm{p}<0.0001)$ and with increasing WHR $(\mathrm{p}<0.0001)$. Elevated

Table 2 Demographics and other characteristics of subjects with and without hepatic steatosis according to cortisol tertiles.

\begin{tabular}{|c|c|c|c|c|c|c|}
\hline & \multicolumn{3}{|c|}{ Subjects without hepatic steatosis } & \multicolumn{3}{|c|}{ Subjects with hepatic steatosis } \\
\hline & $\begin{array}{l}\text { Tertile } 1 \\
(n=327)\end{array}$ & $\begin{array}{l}\text { Tertile } 2 \\
(n=323)\end{array}$ & $\begin{array}{l}\text { Tertile } 3 \\
(n=326)\end{array}$ & $\begin{array}{l}\text { Tertile } 1 \\
(\mathrm{n}=116)\end{array}$ & $\begin{array}{l}\text { Tertile } 2 \\
(n=117)\end{array}$ & $\begin{array}{l}\text { Tertile } 3 \\
(n=117)\end{array}$ \\
\hline \multicolumn{7}{|l|}{ Demographics } \\
\hline \multicolumn{7}{|l|}{ Gender n (\%) } \\
\hline Female & $208(63.6)$ & $186(57.6)$ & $151(46.3)^{\mathrm{a}}$ & $44(37.9)$ & $41(35.0)$ & $32(27.4)$ \\
\hline Male & $119(36.4)$ & $137(42.4)$ & $175(53.7)$ & $72(62.1)$ & $76(65.0)$ & $85(72.7)$ \\
\hline Age (years) & $40.9(11.2)$ & $40.3(12.3)$ & $36.0(12.6)^{a}$ & $47.9(10.1)$ & $50.4(10.7)$ & $47.0(12.5)$ \\
\hline $\operatorname{BMI}\left(\mathrm{kg} / \mathrm{m}^{2}\right)$ & $24.1(3.8)$ & $24.5(4.2)$ & $23.7(3.5)$ & $29.9(4.0)$ & $29.6(4.8)$ & $29.4(4.8)$ \\
\hline WHR & $0.8(0.1)$ & $0.8(0.1)$ & $0.8(0.1)$ & $0.9(0.1)$ & $0.9(0.1)$ & $0.9(0.1)$ \\
\hline \multicolumn{7}{|c|}{ Laboratory parameters } \\
\hline $\operatorname{ALT}(\mathrm{U} / \mathrm{l})$ & $12.9(4.9)$ & $13.3(5.0)$ & $14.1(6.3)^{b}$ & $20.6(10.3)$ & $19.6(10.0)$ & $21.9(12.1)$ \\
\hline AST (U/I) & $8.8(2.3)$ & $9.0(2.1)$ & $9.2(2.9)$ & $10.9(4.4)$ & $10.6(4.3)$ & $12.2(7.1)$ \\
\hline GGT (U/I) & $10.9(12.9)$ & $10.9(8.5)$ & $12.1(13.9)$ & $17.8(14.0)$ & $18.9(18.3)$ & $22.0(22.6)$ \\
\hline $\operatorname{AP}(\mathrm{U} / \mathrm{I})$ & $78.9(22.1)$ & $79.9(22.7)$ & $82.6(24.5)$ & $84.7(21.3)$ & $87.5(22.2)$ & $86.1(23.0)$ \\
\hline Triglycerides (mmol/l) & $1.3(0.8)$ & $1.4(1.0)$ & $1.3(0.8)$ & $2.4(1.7)$ & $2.2(1.4)$ & $2.2(1.4)$ \\
\hline Cholesterin (mmol/l) & $5.3(1.0)$ & $5.5(1.1)$ & $5.2(1.0)^{c}$ & $5.9(1.1)$ & $5.8(1.1)$ & $5.8(1.0)$ \\
\hline \multicolumn{7}{|l|}{ Sonographic findings } \\
\hline \multicolumn{7}{|l|}{ Hepatic steatosis n (\%) } \\
\hline No & $327(100)$ & $323(100)$ & $326(100)$ & - & - & - \\
\hline Grade I & - & - & - & $46(39.7)$ & $54(46.2)$ & $48(41.0)$ \\
\hline Grade II/III & - & - & - & $70(60.3)$ & $63(53.8)$ & $69(59.0)$ \\
\hline
\end{tabular}

Values are mean \pm SD

ALT: Alanine aminotransferase; AP: Alkaline phosphatase; AST: Aspartate aminotransferase; GGT: -Glutamyl transferase; HDL: High-density lipoprotein; LDL: low-density lipoprotein; WHR: waist-to-hip ratio

${ }^{\mathrm{a}} \mathrm{p}<0.001 ;{ }^{\mathrm{b}} \mathrm{p}<0.05 ;{ }^{\mathrm{c}} \mathrm{p}<0.01$ 
levels of ALT $(p<0.0001)$ and triglycerides $(p=0.0001)$ were associated positively with NAFLD. AST, GGT, AP, and cholesterol levels were not associated with NAFLD. Also, total cortisol concentrations showed no significant association with NAFLD $(\mathrm{p}=0.1518)$.

\section{Discussion}

$\nabla$

In the present random population sample, the prevalence of NAFLD was $26.2 \%$. This corresponds with the prevalences of $23 \%$ to $31 \%$ reported in the literature for developed countries $[2,20-$ 22 ]. Differences in prevalence rates result from the characteristics of the studied population. In Asia, the reported prevalences of $11.5-20.8 \%$ are significantly lower $[23,24]$ than in European countries. Recently, however, the variable increases in obesity and diabetes in different Asian populations is reflected in the prevalence of NAFLD ranging from only $5 \%$ to as high as $32 \%$ [25], showing that not only obesity and diabetes, but also ethnicity have an influence on the prevalence of NAFLD. In the USA, the prevalence rates of $45 \%, 33 \%$, and $24 \%$ for Hispanics, Caucasians, and African-Americans, respectively, would appear to bear this out [22].

Divergent prevalence data may also arise by reason of different diagnostic methods to identify NAFL [26]. Compared to MRI, the sensitivity of sonography for determining the fat content of the liver, especially when there is a low fat content, is weak [27]. Thus, when the fat content of the liver is $<20 \%$, the prevalence of NAFLD could be underestimated [28]. Liver biopsy remains the gold standard for confirming the diagnosis of NAFLD and for measuring the fat content in this organ [9]; nevertheless, sonographic diagnosis of fatty liver is easy to perform and has an established role in hospitals and outpatient settings [29]. It has proven to be valuable in our study although NASH and fibrosis

Table 3 Multiple logistic regression analysis to assess the independent predictors of hepatic steatosis.

\begin{tabular}{|c|c|c|}
\hline Variable & OR (95\% Cl) & p-Value \\
\hline Gender & Ref. & \\
\hline Female & $1.578(1.083-2.297)$ & 0.0174 \\
\hline \multicolumn{3}{|l|}{ Male } \\
\hline \multicolumn{3}{|l|}{ Age } \\
\hline $18-30$ & Ref. & $<0.0001$ \\
\hline $31-40$ & $3.063(1.528-6.138)$ & \\
\hline $41-50$ & 3.776 (1.823-7.819) & \\
\hline $51-65$ & $7.271(3.548-14.901)$ & \\
\hline \multicolumn{3}{|l|}{$\mathrm{BMI}$} \\
\hline$<25$ & Ref. & $<0.0001$ \\
\hline $25-30$ & $4.092(2.662-6.290)$ & \\
\hline$\geq 30$ & $13.502(8.161-22.340)$ & \\
\hline \multicolumn{3}{|l|}{ WHR } \\
\hline normal & Ref. & $<0.0001$ \\
\hline elevated & $2.536(1.760-3.653)$ & \\
\hline $\operatorname{ALT}(\mathrm{U} / \mathrm{I})$ & $1.092(1.053-1.132)$ & $<0.0001$ \\
\hline AST (U/I) & $1.014(0.938-1.097)$ & 0.7241 \\
\hline GGT (U/I) & $0.994(0.981-1.006)$ & 0.3081 \\
\hline $\mathrm{AP}(\mathrm{U} / \mathrm{I})$ & $0.993(0.985-1.001)$ & 0.0987 \\
\hline Cholesterol (mmol/l) & $1.131(0.956-1.339)$ & 0.1920 \\
\hline Triglycerides (mmol/l) & $1.360(1.162-1.592)$ & 0.0001 \\
\hline Total cortisol (nmol/l) & $1.001(1.000-1.0002)$ & 0.1518 \\
\hline
\end{tabular}

cannot be adequately recognised and distinguished from benign NAFL [8].

In the present study, the NAFLD risk in the general population increased significantly with age. This result corresponds with reports in the literature [26]. The influence of age on the incidence of NAFLD is particularly evident in women $[30,31]$. In our population with a $50.1 \%$ proportion of women, the prevalence of NAFLD was $17.3 \%$ for women and $35.1 \%$ men. The difference between the sexes is already well known. Compared to rates observed in women, NAFLD is found about twice as frequently in men in studies in the USA ( $42 \%$ in men and $24 \%$ in women [22]), Israel ( $38 \%$ in men and $21 \%$ in women [20]), and China (15.8\% in men and 7.5\% in women [30]), but not in Hispanics and AfricanAmericans [22].

In our study of healthy subjects, risk factors for NAFLD such as increasing age, male sex, increased levels of BMI, WHR, ALT, and triglycerides were associated with NAFLD corresponding to reports in the literature $[21,25,31]$. No association was observed between the presence of NAFLD and serum cortisol concentrations. The lack of correlation between NAFLD and serum cortisol does not rule out that glucocorticoids nevertheless play a pathogenetic importance in the development of NAFLD. Supporting that hypothesis is the finding that development of severe fatty liver was observed under treatment with the synthetic glucocorticoid, dexamethasone [32]. In line with these clinical observations, animal studies demonstrate that dexamethasone increases hepatic triglyceride synthesis and intrahepatic storage of triglycerides [33]. To accompany this pathogenetic significance, it is also suggested that the presence of NAFLD is correlated with increased activity of the pituitary-adrenocortical axis (HPA) resulting in subclinical hypercortisolism [34,35]. Compared to controls, patients with NAFLD show an increased cortisol turnover $[19,35]$. The increased excretion of cortisol metabolites in urine could lead to compensatory increases of cortisol secretion and furthermore to a subclinical hypercortisolism. A corresponding increased cortisol secretion could not be detected in our study by simply determining the concentration of cortisol in serum.

Recently it was proven that the activity of $11 \beta$-hydroxysteroid dehydrogenase type 1 (11ß-HSD1) in visceral adipose tissue leads to portal hypercortisolism and is associated with NAFLD [36]. Visceral adipose tissue is of considerable importance in terms of cardiovascular risk. Visceral fat is positively associated with waist circumference, blood pressure, triglycerides and negatively with HDL-cholesterol [37], and it also is significant in terms of the glucocorticoid metabolism [38]. At the same subcutaneous fat mass, male adolescents with NAFLD have more visceral fat than female adolescents with NAFLD [39]. Furthermore, the visceral fat mass correlates closely with a fatty liver [40]. Compared to women, increased visceral fat in men and in persons with increased BMI and/or an increased WHR might explain the different prevalences of NAFLD in men and women and the high prevalence in individuals with abdominal obesity, both in our own and in other studies $[20,22,30]$.

The present study has weaknesses and strengths. One strength of the study is the large number of healthy persons examined $(n=1348)$. For the diagnosis of fatty liver, sonography was selected as a noninvasive, fast, and low-cost method. Medical ultrasonics has proven to be sufficiently suitable in both in- and outpatient settings for establishing the diagnosis. Because of the lower sensitivity compared to the MRI, the high prevalence of NAFLD may have been underestimated with sonography. How- 
ever, for screening under field conditions ultrasonography is the only practical method for estimating the fat content of the liver. A weakness of the study is that not all investigations took place in the morning. Instead, examinations were performed between $1 \mathrm{PM}$ and 9PM and the serum cortisol reference range for the second half of the day was used. Although the schedule of each activity was known and every procedure has been previously explained and performed under quiet conditions, it cannot be excluded that individual stress influenced cortisol levels in some cases. Another weakness of the study is that only the current cortisol levels were quantified. The excretion of cortisol metabolites in 24-h urine could not be measured in the context of the study and no functional studies were performed. Furthermore, women taking oral contraceptives have not been excluded from the study, even if there is an influence on the cortisol value. This was done in favour of better comparability of men and women with approximately equal numbers of participation in this study. In addition, after excluding women taking estrogens, the informative values would have been too low. In 350 of the 1326 study participants, ultrasound returned findings consistent with fatty liver. The small number of subjects limits the informative value. Nonetheless, the well-known associations between fatty liver and anthropometric measures, and with ALT and triglycerides were confirmed.

\section{Conclusion}

\section{$\nabla$}

The present population-based cross-sectional study found no association between serum cortisol concentrations and the presence of NAFLD. The determination of total cortisol in serum would appear to be of no independent value in the diagnosis of NAFLD in routine clinical practice. Nevertheless, glucocorticoid metabolism is an important factor in the pathogenesis of NAFLD. Ultrasonography of the liver is a practical, reproducible, and cost-effective method for detecting NAFLD.

\section{Acknowledgements}

Members of the EMIL-Study-Group (in alphabetical order)

Adler G, Armsen A, Banzhaf H-M, Bauerdick M, Bertling U, Boehm BO, Brandner BO, Brockmann SO, Deckert M, Dingler C, Eggink S, Fuchs M, Gaus W, Goussis H, Gruenert A, Haenle MM, Hampl W, Haug C, Hay B, Huetter M-L, Imhof A, Kern P, Kimmig P, Kirch A, Klass D, Koenig W, Kratzer W, Kron M, Manfras B, Meitinger K, Mertens T, Oehme R, Pfaff G, Piechotowski I, Reuter S, Romig T, von Schmiesing AFA, Steinbach G, Tourbier M, Voegtle A, Walcher T, Wolff S.

\section{Conflict of Interest \\ $\nabla$}

The authors declare that they have no conflict of interest.

\section{Affiliations}

${ }^{1}$ Department of Internal Medicine I, University Hospital Ulm, Ulm, Germany ${ }^{2}$ Department of diagnostic and interventional Radiology, University Hospital Ulm, Ulm, Germany

${ }^{3}$ Louis Stokes Cleveland Department of Veterans Affairs Medical Center, Cleveland, Ohio, USA

${ }^{4}$ Department of Internal Medicine II, University Hospital Ulm, Ulm, Germany ${ }^{5}$ Lee Kong Chian School of Medicine, Imperial College London and Nanyang Technological University, Singapore

${ }^{6}$ Institute of Epidemiology and Medical Biometry, Ulm, Germany

\section{References}

1 Cohen JC, Horton JD, Hobbs HH. Human fatty liver disease: old questions and new insights. Science 2011; 332: 1519-1523

2 Bhala N, Jouness RI, Bugianesi E. Epidemiology and natural history of patients with NAFLD. Curr Pharm Des 2013; 19: 5169-5176

3 Musso G, Gambino R, Cassader M, Pagano G. Meta-analysis: Natural history of non-alcoholic fatty liver disease (NAFLD) and diagnostic accuracy of non-invasive tests for liver disease severity. Ann Med 2011; 43: 617-649

4 Szczepaniak LS, Nurenberg P, Leonard D, Browning JD, Reingold LS Grungy S, Hobbs HH, Dobbins $R L$. Magnetic resonance spectroscopy to measure hepatic triglyceride content: prevalence of hepatic steatosis in the general population. Am J Physiol Endocrinol Metab 2005; 288: E462-E468

5 WHO. Expert Committee on Physical Status. The Use and Interpretation of Anthropometry: report of a WHO expert committee (WHO technical report series): World Health Organisation, Genf: 1995; 427-437

6 Charatcharoenwitthaya $P$, Lindor KD. Role of radiologic modalities in the management of non-alcoholic steatohepatitis. Clin Liver Dis 2007; 11: 37-54

7 Hamaguchi M, Kojima T, Itoh Y, Fujii K, Nakajiama T, Kato T, Takeda $N$ Okuda J, Ida K, Kawahito Y, Yoshikawa T, Okanoue T. The severity of ultrasonographic findings in non-alcoholic fatty liver disease reflects the metabolic syndrome and visceral fat accumulation. Am J Gastroenterol 2007; 12: 2708-2715

8 Mendez-Sanchez N, Arrese M, Zamora-Valdes D, Uribe M. Current concepts in the pathogenesis of nonalcoholoic fatty liver disease. Liver Int 2007; 27: 423-433

9 Mishra P, Younossi ZM. Abdominal Ultrasound for Diagnosis of Nonalcoholic Fatty liver Disease (NAFLD). Am J Gastroenterol 2007; 102: 2716-2717

10 Westerbacka J, Lammi K, Hakkinen AM, Rissanen A, Salminen I, Aro A, Yki-Järvinen $H$. Dietary fat content modifies liver fat in overweight nondiabetic subjects. J Clin Endocrinol Metab 2005; 90: 2804-2809

11 Tamura S, Shimomura I. Contribution of adipose tissue and de novo lipogenesis to nonalcoholic fatty liver disease. J Clin Invest 2005; 115: 1139-1142

12 McDevitt RM, Bott SJ, Harding M, Coward WA, Bluck LJ, Prentice AM. De novo lipogenesis during controlled overfeeding with sucrose or glucose in lean and obese women. Am J Clin Nutr 2001; 47: 737-746

13 Hudgins LC, Hellerstein M, Seidman C, Neese R, Diakun J, Hirsch J. Human fatty acid synthesis is stimulated by a eucaloric low fat, high carbohydrate diet. J Clin Invest 1996; 97: 2081-2091

14 Schwarz JM, Linfoot P, Dare D, Aghajanian K. Hepatic de novo lipogenesis in normoinsulinemic and hyperinsulinemic subjects consuming high-fat, low-carbohydrate and low fat, high-carbohydrate isoenergetic diets. Am J Clin Nutr 2003; 77: 43-50

15 Stanhope KL, Schwarz JM, Keim NL, Griffin SC, Bremer AA, Graham JL, Hatcher B, Cox CL, Dyachenko A, Zhang W, McGahan JP, Seibert A, Kraus RM, Chiu S, Schaefer EJ, Ai M, Otokazawa S, Nakajima K, Nakano T, Beysen C, Hellerstein MK, Berglund L, Havel PJ. Consuming fructosesweetened, not glucose-sweetened, beverages increases visceral adiposity and lipids and decreases insulin sensitivity in overweight/ obese humans. J Clin Invest 2009; 119: 1322-1334

16 Buechler C, Wanninger J, Neumeier M. Adiponectin, a key adipokine in obesity related liver diseases. World J Gastroenterol 2011; 17: 2801-2811

17 Schwimmer JB, Celedon MA, Lavine JE, Salem R, Campbell N, Schork NJ, Shiehmorteza M, Yokoo T, Chavez A, Middleton MS, Sirlin CB. Heritability of nonalcoholic fatty liver disease. Gastroenterology 2009; 136: $1585-1592$

18 Hooper AJ, Adams LA, Burnett JR. Genetic determinants of hepatic steatosis in man. J Lipid Res 2011; 52: 593-617 
19 Ahmed A, Rabbitt E, Brady T, Brown C, Guest P, Bujalska IJ, Newsome PN, Hubscher S, Elias E, Adams DH, Tomlinson JW, Stewart PM. A switch in hepatic cortisol metabolism across the spectrum of non-alcoholic fatty liver disease. PloS One 2012; 7: e29531

20 Zelber-Sagi S, Nitzan-Kaluski D, Halpern T, Oren R. Prevalence of primary non-alcoholic fatty liver disease in a population-based study and its association with biochemical and anthropometric measures. Liver Int 2006; 26: 856-863

21 Bedogni G, Bellentani S, Miglioli L, Masutti F, Passalacqua M, Castiglione A, Tribelli $C$. The fatty liver index: a simple and accurate predictor of hepatic steatosis in the general population. BMC Gastroenterology 2006; 6: 331

22 Browning JD, Szczepaniak LS, Dobbins R, Nuremberg P, Horton JD, Cohen $J C$, Grundy SM, Hobbs HH. Prevalence of hepatic steatosis in an urban population in the United States: impact of ethnicity. Hepatology 2004; 40: $1387-1395$

23 Chen CH, Huang MH, Yang JC, Nien CK, Yang CC, Yeh YH, Yueh SK. Prevalence of risk factors of nonalcoholic fatty liver disease in adult population of taiwan: metabolic significance of nonalcoholic fatty liver disease in nonobese results. J Clin Gastroenterol 2006; 40: 745-752

24 Fan JG. Epidemiology of alcoholic and nonalcoholic fatty liver disease in China. J Gastroenterol Hepatol 2013; 28 (Suppl 1): 11-17

25 Amarapurkar DN, Hashimoto E, Lesmana LA, Sollano JD, Chen PJ, Goh KL, Asia-Pacific Working Party on NAFLD. How common is non-alcoholic fatty liver disease in the Asia-Pacific region and there local differences? J Gastroenterol Hepatol 2007; 22: 788-793

26 Bellentani S, Scaglioni F, Marino M, Bedogni G. Epidemiology of nonalcoholic fatty liver disease. Dig Dis 2010; 28: 155-161

27 Fabbrini E, Conte C, Magkos F. Methods for assessing intrahepatic fat content and steatosis. Curr Opin Clin Nutr Metab Care 2009; 12: 474-481

28 Dasarathy S, Dasarathy J, Khiyami A, Joseph R, Lopez R, McCullough $A J$. Validity of real ultrasound in the diagnosis of hepatic steatosis: a prospective study. J Hepatol 2009; 51: 1061-1067

29 Kratzer W, Kron M, Hay B, Pfeiffer MM, Kächele V. Prevalence of cholelithiasis in South Germany - an ultrasound study of 2498 persons of a rural population. Z Gastroenterol 1999; 37: 1157-1162

30 Shen L, Fan JG, Shao Y, Zeng MD, Wang JR, Luo GH, Li JQ Chen SY. Prevalence of nonalcoholic fatty liver among administrative officers in Shanghai: an epidemiological survey. World J Gastroenterol 2003; 9: $1106-1110$
31 Clark JM. The epidemiology of nonalcoholic fatty liver disease in adults. J Clin Gastrenterol 2006; 40 (Suppl 1): S5-S10

32 Dourakis SP, Sevastianos VA, Kaliopi P. Acute severe steatohepatitis related to prednisolone therapy. Am J Gastrenterol 2002; 97: 10741075

33 Dolinsky VW, Douglas DN, Lehner R, Vance DE. Regulation of hepatic microsomal triacylglycerol lipolysis and re-esterification by the glucocorticoid dexamethasone. Biochemical J 2004; 378: 967-974

34 Targher G, Bertolini L, Rodella S, Zoppini G, Zenari L, Falezza G. Associations between liver histology and cortisol secretion in subjects with nonalcoholic fatty liver disease. Clin Endocrinol 2006; 64: 337-341

35 Konopelska S, Kienitz T, Hughes B, Pirlich M, Bauditz J, Lochs H, Strasburger CJ, Stewart PM, Quinkler M. Hepatic 11beta-HSD1 mRNA expression in fatty liver and nonalcoholic steatohepatitis. Clin Endocrinol Oxf 2009; 70: 554-560

36 Candia R, Riquelme A, Baudrand R, Carvajal CA, Morales M, Solis N, Pizarro M, Escalona A, Carrasco G, Boza C, Pérez G, Padilla O, Cerda J, Fardella $C E$, Arrese M. Overexpression of $11 \beta$-hydroxysteroid dehydrogenease type 1 in visceral adipose tissue and portal hypercortisolism in non-alcoholic fatty liver disease. Liver Int 2012; 32: 392-399

37 Shiina Y, Homma Y. Relationships between the visceral fat area on CT and coronary risk factor markers. Intern Med 2013; 52: 1775-1780

38 Debono M, Prema A, Hughes TJ, Bull M, Ross RJ, Newell-Price J. Visceral fat accumulation and postdexamethasone serum cortisol levels in patients with adrenal incidentaloma. J Clin Endocrinol Metab 2013; 98: 2383-2391

39 Ayonrinde OT, OlynykJK, Beilin LJ, Mori TA, Pennell CE, de Klerk N, Oddy WH, Shipman P, Adams LA. Gender-specific differences in adipose distribution and adipocytokines influence adolescent nonalcoholic fatty liver disease. Hepatology 2011; 53: 800-809

40 Speliotes EK, Massaro JM, Hoffmann U, Vasan RS, Meigs JB, Sahani DV, Hirschhorn JN, O'Donell CJ, Fox CS. Fatty liver is associated with dyslipidemia and dysglycemia independent of visceral fat: the Framingham Heart Study. Hepatology 2010; 51: 1979-1987 